\title{
Rhetorical Interpretation of Abstracts in Sci-Tech Theses Based on Burke's Identification Theory
}

\author{
Jihong Zhong ${ }^{1}$ \\ ${ }^{1}$ School of Foreign Languages, Jiangsu University, Zhenjiang, Jiangsu, China \\ Correspondence: Jihong Zhong, School of Foreign Languages, Jiangsu University, Zhenjiang, Jiangsu, China. \\ E-mail: 1679135843@qq.com
}

Received: February 22, 2017

Accepted: April 10, 2017 Online Published: April 12, 2017

doi: 10.5539/elt.v10n5p68

URL: http://doi.org/10.5539/elt.v10n5p68

\begin{abstract}
Abstract of a thesis is the brief and accurate representation of the thesis, with the important function of persuading readers to read on the thesis. So how the writer constructs the abstract and wins readers' recognition is our main focus. On the basis of Burke's Identification Theory, this paper analyzed 10 abstracts from Nature from content and form perspective respectively. The results show that identifications by sympathy, by antithesis and by inaccuracy are three main content identification strategies and conventional form is the main form identification strategy, which combine together to improve the objectivity and persuasion of abstracts.
\end{abstract}

Keywords: Kenneth Burke, identification, abstract, content, form

\section{Introduction}

Abstract is an important component of a thesis, which is believed to be the "condensed genre" (Swales, 1990) of the thesis. It not only conveys the most fundamental and valuable information, but also helps the author to promote their research and to persuade discourse community. Abstract is an important means to win recognition in science community and to achieve "membership" and "credibility" (Hyland, 2000) in the academic field.

Nowadays, researches on sci-tech abstract is mainly focused on the following two aspects. The first one is on the analysis of move structure. Hoey (1983) puts forward the "problem-solution" pattern of abstract discourse while Swales (1990), Bhatia (1993) proposes introduction-methods-results-discussion (IMRD) mode of abstract genre. The second focus of abstract research is on the linguistic features of abstract, such as the promoting language strategies (Yang, 2012), grammatical features of tense, mood, modality, hedges and pronouns in abstract (Zhou, 2014; Wang, 2014; Hua \& Jiang, 2015). These researches have paid enough attention to the objective description and explanation of abstracts; however, it still remains unclear how abstracts help to win recognition of readers and science community.

Based on Kenneth Burke's identification theory, this paper aims at finding out how abstracts win recognition from both content and form perspective, which will surely help the construction of sci-tech thesis abstract.

\section{Theoretical Framework}

Kenneth Burke is the pioneer and founder of new rhetoric, who has made penetrating influence on new rhetorical views in the $20^{\text {th }}$ century. Burke believes that "the basic function of rhetoric (is) the use of words by human agents to form attitudes or to induce actions in other human agents" (Burke, 1969). According to Burke, while the key term for classical rhetoric is persuasion and its emphasis is upon deliberate design, the key conception for new rhetoric is identification. When people want to cooperate with others, they first must overcome the divisions that separate them and try to identify themselves with and to induce cooperation from other individuals. When overcoming the divisions, the speaker or writer will adapt themselves in the choice of words, postures, tones, attitudes, and even views to the audience to achieve identification. So the speaker or writer will adopt their speaking or writing mode and will use different rhetorical method to induce the audience to form certain attitudes or to take actions. So identification can be both a deliberative device, as when the speaker or writer seeks to identify himself with the audience, and an end, as when people are eager to identify themselves with some group or other.

In Burke's identification theory, three basic prerequisites are embodied: first, a speaker identifies aspects of experience through language; then identification goes through as the use of language negotiates identity within 
groups; and then rhetoric negotiates personal identity. Besides these, Burke puts forward basic strategies and forms in achieving identification, which include content and form identification. Content identification includes identification by sympathy, by antithesis and by inaccuracy, while form identification includes rhetorical form, conventional form, repetitive form and progressive form. Content identification is closely related to form identification while form identification helps to promote content identification.

Sympathy is basically regarded as one of the social passions, which connects men together in a civilized society. So identification by sympathy is actually taking advantage of similar emotional background and perception of different groups. Identification by antithesis is to set up a common enemy, or an urgent problem, or a hazardous status, thus urged to unite, which promotes cooperation temporarily. Identification may also be achieved by inaccurate cognition, unconsciously or subconsciously, mistaking what happens to others will naturally happen to themselves.

Rhetoric devices, such as antithesis, climax, repetition, help to gain recognition and identification from the audience when identification in form will trigger the identification in proposition as belief (Burke 1969). Conventional form refers to the reasonable expectation of certain genre before reading (Ju, 2011), which may be the conventionalized global or local features of certain genre. Repetitive form means to repeat one feature or one viewpoint in different forms while progressive form refers to process of argumentation, which usually takes the form of syllogism of major premises, minor premises and conclusion or the form of deductive reasoning of qualitative and quantitative change (Deng, 2011).

Scientific and technological paper abstracts are very important carriers for writers to gain identification among scientific community, so how writers try to gain identification by means of content and form is very crucial and that is the research point of this essay.

\section{Research Design}

\subsection{Research Background}

Traditionally speaking, scientific paper is supposed to be objective, rigorous, and rational, which is always based on facts from observation and experiment, with no rhetoric or polish. With the rhetoric turn in philosophy of science, more and more researchers begin to realize the importance of rhetoric in scientific papers. Ziman (1985) believes that scientific paper is also normative language expression. From writers' perspective, a scientific paper is not only to report what they have done, but also to convince other researchers of the correctness of their finding, or at least of self-justification of their finding, which are the rhetoric purposes of any scientific paper. Li and Zhu (2005) find out that superficially, a scientific paper is to report the achievement in the lab to scientific community, but actually, any scientific paper is to win support of their own view and to pose a difficult problem to rivals with the use of rhetoric means. All these indicate that scientific papers are not absolutely natural language expression, but penetratingly persuasive and convincing.

Abstracts, as condensed genre of scientific papers, play the role of "directing the readers' choice of reading or quoting, conference organizers' choice of accepting or rejecting of some paper" (Lores, 2004). One of the most important roles of abstracts is to attract readers (Hyland \& Tse, 2005; Ge, etc., 2005) and to persuade readers to read on the papers (Hyland, 2000) and to gain identification from readers, thus achieve membership among scientific community.

Burke has constructed basic strategies of identification from both content and form. Content identification includes identification by sympathy, by antithesis and by inaccuracy while form identification includes rhetorical form, conventional form, repetitive form and progressive form.

Identification by sympathy stresses similar parts of both sides. In 2009, when Obama visited Shanghai, he said he was also a basketball fan and Yao Ming (Shanghai basketball player who played basketball in NBA) was the symbol of Sino-American people's love of basketball. By mentioning Yao Ming and basketball, Obama tried to highlight similarity of both sides and to shorten distance between each other, thus achieving identification (Zhong et al., 2014). In abstracts, writers may emphasize the importance or urgency of the topic, which will arouse interest of those concerned and attract them to read on the papers.

\section{Example 1:}

Article 1: Low-valent late transition-metal catalysis has become indispensable to chemical synthesis, but ...

Article 2: Antibiotic resistance is spreading faster than the introduction of new compounds into clinical practice, causing a public health crisis.

Article 5: Ryanodine receptors (RyRs) mediate the rapid release of calcium $\left(\mathrm{Ca}^{2+}\right)$ from intracellular stores into 
the cytosol, which is essential for numerous cellular functions including excitation-contraction coupling in muscle.

In the above examples, the writers use "indispensable, essential" to emphasize the importance of the topic and use "crisis" to indicate the urgency of antibiotic resistance, which helps to trigger similar experience and empathize with the writer, thus arousing their interest to read on, even to accept the authors' view.

Identification by antithesis is to set up a common opponent, which may be some person, or some thing, or some viewpoint, or even the environment problem. In 2009, more than 85 heads of state or government and environmental ministers from 192 countries participated in Climate Conference in Copenhagen and discussed how to deal with climate change in the future. Although these countries have different ideological systems and regime modes, they realized that the same problem threatened the future of humans, so they chose to cooperate. In abstracts, writers may establish a research niche of present research or point out that certain research is still unknown, which will be regarded as the common opponent to trigger identification.

\section{Example 2:}

Article 3: However, how this regulation is encoded in the messenger RNA sequence remains largely unknown.

Article 4: The molecular mechanism underlying the complex regulation of RyRs is poorly understood.

In the above examples, writers use "largely unknown, poorly understood" to establish the niche and set it up as the common opponent to achieve temporary identification.

Identification by inaccuracy is always achieved unconsciously or subconsciously. "We, all, everyone" are used to obscure the boundary of writers and audience, which helps to drag audience to the same frontline with writers.

Example 3:

Article 6: Here we conducted neural recordings in bats, mammals well-adapted to 3D spatial behaviors...

Article 10: This model allowed us to develop and validate new hypotheses about secondary wall gene regulation under abiotic stress.

In the above examples, "we" and "us" are used to refer to writers, which may also include the readers. Readers are dragged into the process of experiment and report unconsciously, which will help them to be convinced and persuaded.

Rhetoric devices help to explain and illustrate. When nominating new concepts or new phenomena or explaining abstract facts, researchers prefer to find out easily-understood words from in-vocabulary and transplant them into newly-appeared things or to concretize abstractions for better understanding. Metaphor is one of the widely-used rhetoric devices while rhetorical devices, like analogy, personification are also on the list (Zhong etc., 2014).

Conventional form refers to the conventionalized form of certain genre. Sci-tech abstracts usually follow four-move-mode of IMRD, introduction, method, results, discussion (Bhatia, 1993), or four-move-mode of SPRE, situation, problem, response, evaluation (Hoey, 1983). With conventional and rational move structure, sci-tech abstracts take on logicality and organization, which is convincing enough to win support of readers.

Repetitive form is to use different forms to repeat and emphasize one viewpoint while progressive form tries to adopt certain argumentation method.

\subsection{Data Collection}

Science magazine Nature began its publication in 1869, which ranks among one of the best international scientific magazines. Its impact factor in 2014 is 41.456 . So articles in Nature can be regarded as typical and representative in sci-tech research field. Then articles in Nature are chosen as research object. Ten articles published in 2015 have been chosen, all of which are empirical researches, which are believed to share similar rhetorical structures. Table 1 lists the basic information of the research object. 
Table 1. Basic information of research data

\begin{tabular}{lll}
\hline Title of articles & Word num. & Sentence num. \\
\hline 1 Stable gold(III) catalysts by oxidative addition of a carbon-carbon bond & 136 & 6 \\
2 A new antibiotic kills pathogens without detectable resistance & 167 & 9 \\
3 RNA regulons in Hox 5' UTRs confer ribosome specificity to gene regulation & 154 & 8 \\
4 Architecture and conformational switch mechanism of the ryanodine receptor & 145 & 8 \\
5 Structure of a mammalian ryanodine receptor & 159 & 7 \\
6 Three-dimensional head-direction coding in the bat brain & 156 & 7 \\
7 Human gut Bacteroidetes can utilize yeast mannan through a selfish mechanism & 159 & 6 \\
8 Internal models direct dragonfly interception steering & 163 & 9 \\
9 Forcing, feedback and internal variability in global temperature trends & 195 & 7 \\
10 An Arabidopsis gene regulatory network for secondary cell wall synthesis & 151 & 8 \\
Average number & 158 & 7.5 \\
\hline
\end{tabular}

\subsection{Data Analysis}

After collecting the data, we make careful study on the content identification and form identification strategies.

3.3.1 Data of Identification by Sympathy

Bold-faced words in the following examples indicate how identification is achieved by sympathy.

Example 4

Article 1: Low-valent late transition-metal catalysis has become indispensable to chemical synthesis, but ...

Article 2: Antibiotic resistance is spreading faster than the introduction of new compounds into clinical practice, causing a public health crisis.

Article 3: Emerging evidence suggests that the ribosome has a regulatory function in directing how the genome is translated in time and space.

Article 4: Numerous mutations in RyRs have been associated with human diseases.

Article 5: Ryanodine receptors (RyRs) mediate the rapid release of calcium $\left(\mathrm{Ca}^{2+}\right)$ from intracellular stores into the cytosol, which is essential for numerous cellular functions including excitation-contraction coupling in muscle.

Article 9: Most present-generation climate models simulate an increase in global-mean surface temperature (GMST) since 1998, ...

Article 10: The plant cell wall is an important factor for determining cell shape, function and response to the environment.

Among the ten abstracts, three of them use adjectives, like indispensable, essential, important, to indicate the importance of the topic; two use phrases, like causing a public health crisis, associated with human disease, to show the urgency of the topic and two use phrases, like emerging evidence, most climate models, to indicate that the topic is widely concerned.

\subsubsection{Data of Identification by Antithesis}

Bold-faced words in the following examples indicate how identification is achieved by antithesis.

Example 5

Article 1: ..., but homogeneous high-valent transition-metal catalysis is underdeveloped, .... Here we report ...

Article 2: Uncultured bacteria make up approximately $99 \%$ of all species in external environments, and are an untapped source of new antibiotics. ... Here we report ...

Article 3: However, how this regulation is encoded in the messenger RNA sequence remains largely unknown. Here we uncover... 
Article 4: The molecular mechanism underlying the complex regulation of RyRs is poorly understood. Using electron cryomicroscopy, here we determine...

Article 5: Lack of sufficient structural detail has impeded understanding of RyR gating and regulation. Here we report...

Article 6: However, it remains unclear whether a three-dimensional (3D) compass exists in the brain. Here we conducted...

Article 7: The influence of yeast mannan on the ecology of the human microbiota is unknown. Here we show...

Article 8: Whether invertebrates use such models remains unclear. Here we examine...

Article 9: It is unclear to what extent this mismatch is caused by incorrect model forcing, by incorrect model response to forcing or by random factors. Here we analyse...

Article 10: A regulatory hierarchy of developmental switches has been proposed, although the full complement of regulators remains unknown. Here we present...

In all ten abstracts, words or phrases, like underdeveloped, untapped, unknown, poorly understood, lack of sufficient detail, unclear, are used to indicate terra incognita, which should be the opponent of all researchers.

\subsubsection{Data of Identification by Inaccuracy}

Identification by inaccuracy is mainly achieved by the use of first person pronoun "we". The pronoun "we" is commonly used in each article. Table 2 offers the details.

Table 2. Distribution of WE

\begin{tabular}{|c|c|c|c|c|c|c|c|c|c|c|c|}
\hline & Art.1 & Art.2 & Art.3 & Art.4 & Art.5 & Art.6 & Art.7 & Art.8 & Art.9 & Art.10 & Total \\
\hline we & 2 & 4 & 2 & 3 & 2 & 1 & 1 & 2 & 2 & 1 & 20 \\
\hline
\end{tabular}

The highest frequency of "we" in the ten articles is 4 times in one article while the lowest is one, with average number of 2. Occasionally, "our" and "us" also appear in the articles. The high frequency of personal pronoun actually contradicts with the view that scientific paper should use non-person expression to achieve objectivity (Ma, 2001).

\subsubsection{Move Structure}

Move structure is typical form identification strategy. Move structure of each article is carefully analyzed with an attempt to find out the conventional form of sci-tech abstracts.

We find that the common moves in the ten abstracts include the following five: introduction of topic, research niche, research content, research results and evaluation.

On the other hand, no rhetoric form, repetitive form or progressive form have been used in the abstracts owing to space limit.

\section{Results and Discussion}

\subsection{Identification by Sympathy}

Identification by sympathy appeals to emotional resonance between readers and writers. Writers try to sympathize readers by common feelings and experiences to shorten the distance and to gain identification. But sci-tech paper is always objective and rational, ignoring readers' emotion and cognition. So when triggering readers' sympathy, writers mainly focus on the topic both are interested in. Writers will pick up those important or urgent topics, or those practical problems which concern most people, to shorten the distance and to attract readers' attention and to gain identification.

As we have mentioned, adjectives, such as indispensable, essential, important, are used to indicate the importance of the topic; phrases, like causing a public health crisis, associated with human disease, are used to show the urgency of the topic and phrases, like emerging evidence, most climate models, are used to indicate that the topic is widely concerned. Let's take Article 2 as an example.

Example 6

Antibiotic resistance is spreading faster than the introduction of new compounds into clinical practice, causing $a$ public health crisis. 
In this example, the author first introduces the topic, antibiotic resistance and states the fact that antibiotic resistance is spreading faster and points out the problem, causing a public health crisis. Antibiotic resistance is a serious medical problem which is commonly recognized among medical staff. By this commonly-recognized problem, the author tries to trigger readers' similar experience and arouse their expectation. Similar experience and common interest may also arouse readers' active emotion reaction and corresponding reading tendency, which is believed to be one of the strategies to achieve identification by sympathy.

\subsection{Identification by Antithesis}

Identification by antithesis appeals to the common opponent of both writers and readers. In sci-tech abstracts, the terra incognita or the disputable field is the common opponent of both writers and readers. By setting up common opponent and reporting relevant research, writers want their research on this untapped area to be identified. Article 6 is a good example which illustrates it well.

Example 7

However, it remains unclear whether a three-dimensional (3D) compass exists in the brain. Here we conducted neural recordings in bats, mammals well-adapted to 3D spatial behaviors, and found head-direction cells tuned to azimuth, pitch or roll, or to conjunctive combinations of 3D angles, in both crawling and flying bats.

In this example, the writer states that whether a three-dimensional compass exists in the brain remains unclear. So the existence of a three-dimensional compass in the brain is an untapped field of research for both writers and readers, which is believed to be the common opponent. How to solve this problem attracts temporary attention from both sides. By raising a common question is a good way to gain temporary identification. Hyland (2004) puts forward that common questions help to build up closer writer-reader relationship. Then, the writer reports what he has done to solve the problem, to find solution to the problem, hoping to gain recognition and identification of his research from readers.

\subsection{Identification by Inaccuracy}

A typical feature of any sci-tech paper is its non-personal writing way. Writers prefer to use research results, experiment data, scientific concept to personal pronoun to make sure that scientific research is objective, rational and rigorous. But in our research of ten sci-tech abstracts, 20 sentences begin with "we" among 75 sentences, with the frequency of $26 \%$. Every abstract uses at least one "we" as subject. This fully indicates the popular use of personal pronoun in sci-tech abstracts.

In these ten abstracts, "Here we report...", "Here we uncover...", "Here we determine...", "Here we conducted...", "Here we show...", "Here we examine...", "Here we analyse...", "Here we present..." are commonly used. When consulting the author, we find that all are independent authors. So "we" in the sentence actually do not refer to group researchers, but the author himself. So the author chooses to use "we" to drag readers into the process of research and report, which makes readers seemingly participate in the research. In this way, readers unconsciously agree with the writer and accept the view. This is how identification is achieved by inaccuracy.

\subsection{Conventional form Identification}

For the space limit of sci-tech abstracts, each move deserves careful consideration. In a 150-or-so-word long piece, the abstract on one hand tries to attract readers to read on, while on the other hand, it should present research results objectively and rationally. For these, a conventional structure has been developed with long practice among scientific community, such as IMRD by Bhatia (1993) or SPRE by Hoey (1983).

The ten abstracts in research all follow introduction, research niche, research content, results and evaluation, a five-move-mode. In IMRD mode, method and discussion are both important moves while in these ten abstracts, these two do not fall into the move list. Discussion, for the space limit and writing purpose, is not included in abstracts at all while method has been mentioned in only two abstracts only by phrases. Naturally, the key point in abstracts is not on the scientific method or logical discussion, but on potential readers' attention.

Sci-tech abstracts actually comply more with Hoey' (1983) SPRE mode. Introduction functions as situation, which states the topic; research niche is the problem or gap in present research; research content and results together report researchers' response to those problems, and evaluation offers objective and positive comment of present research. This conventional structure has been commonly accepted and adopted among scientific community, which reflects enough logicality and rationality. The conventionalized form of abstracts helps writers gain membership among scientific community and achieve identification of their research. 


\section{Conclusion}

With scientific language turning from lingual tradition to interpretative approach and to rhetoric trend (Guo, 1994), scientific language bears more feature of subjectivity. The strategies that are adopted in how they describe the world, how they convey the knowledge of world, how they publicize their findings, how they win support of their views will greatly influence acceptability of scientific views. Scientists are actually experts of rhetoric who are expertized at using language as weapon to make point and to convince others.

This paper takes ten abstracts from Nature as examples to analyze content and form identification with Burke's new rhetoric as theoretical framework. We find that content identification by sympathy, by antithesis and by inaccuracy is popularly used in sci-tech abstracts. Series of adjectives are used to show the importance or urgency of topic, which shortens the distance between writers and readers by sharing similar focus; the research niche is set up as a common opponent, which paves the way for writers' report of what they have done to deal with the common opponent; and the first person pronoun "we" tries to drag readers into the research to make readers believe that they are also involved in the process of research of report.

In form identification, conventional form is strictly followed, which helps to present main discovery as well as to attract readers' attention. Rhetorical form, repetitive form and progressive form is rarely used in abstracts for space limit.

Scientific research paper is on longer in a prominent position, being cold and distant. On the contrary, it tries every means to shorten the distance to the audience and to win more identification from the audience. The rhetoric trend of scientific language helps win more popularity and support of research findings. And the rhetorical strategies used in the sci-tech abstracts well explain the rhetoric trend.

Though this paper has attempted to investigate the rhetorical strategies used the sci-tech abstracts, some limitations still exist in the research. The data used is relatively limited and all are from a single field of research, which calls for further and deeper research. However, it should be acknowledged that such an incomplete research also has the enlightening meaning in academic paper teaching and writing.

\section{Acknowledgment}

This paper is supported by the grant of the project of School of Foreign Languages, Jiangsu University.

\section{References}

Bhatia. (1993). Analysing Genre: Language Use in Professional Settings. London \& NY: Longman.

Burke, K. (1969). A Rhetoric of Motives. Berkeley: University of California Press.

Crookes, G. (1986). Towards a validated analysis of scientific text structure. Applied Linguistics, 7(1), 57-70. https://doi.org/10.1093/applin/7.1.57

Deng, Z. Y. (2011). Kenneth Burke's Rhetorical Theory and Rhetorical Philosophy. Shanghai: Xuelin Publishing House.

Ge, D. M., \& Yang, R. Y. (2005). A Genre Analysis of Research Article Abstracts. Modern Foreign Languages, 2.

Guo, G. C. (1994). Rhetoric Turn of Science and Its Meaning. Studies in Dialectics of Nature, 12.

Hoey, M. (1983). On the surface of discourse. London: Allen and Unwin.

Hua, L. Q., \& Jiang, Y. (2015). Comparative Study of Hedges in Research Paper Abstracts. Journal of Yangtze University, 6 .

Hyland, K. (2000). Disciplinary Discourses: Social Interactions in Academic Writing. London: Longman.

Hyland, K. (2004). Representing readers in writing: Student and expert practices. Linguistics and Education, 16(4), 363-377. http://dx.doi.org/10.1016/j.linged.2006.05.002

Hyland, K., \& Tse, P. (2005). Hooking the reader: A corpus study of evaluative that in abstracts. English for Specific Purposes, 24(2), 123-139. http://dx.doi.org/10.1016/j.esp.2004.02.002

Ju, Y. M. (2011). Rhetoric of Social Cognition: Theory and Practice. Beijing: Foreign Language Teaching and Research Press.

Li, X. B., \& Zhu, L. J. (2005). Rhetoric in Science Communication. Studies in Science of Science, 4.

Lores, R. (2004). On RA abstracts: From rhetorical structure to thematic organization. English for Specific Purposes, 23(3), 280-302. http://dx.doi.org/10.1016/j.esp.2003.06.001 
Swales, J. (1990). Genre Analysis. Cambridge: Cambridge University Press.

Wang, L. (2014). Multidimensional Study on Features of Research Paper Abstracts. Foreign Languages Research, 3.

Yang, L. (2012). Empirical Study on Promoting Language Use in Research Paper Abstracts. Journal of Xi'an International Studies University, 3.

Zhong, L. F., Zhong, J. B., \& Zhong, J. H., etc. (2014). Discourse and Scientific Communication in English: A Multifacet Perspective. Zhenjiang: Jiangsu University Press.

Zhou, Q. J. (2014). Comparative Study of Meta-Language in Research Paper Abstracts. Foreign Languages Research, 3.

\section{Copyrights}

Copyright for this article is retained by the author(s), with first publication rights granted to the journal.

This is an open-access article distributed under the terms and conditions of the Creative Commons Attribution license (http://creativecommons.org/licenses/by/4.0/). 